\title{
Quando a política se torna inevitável: da arte-em-comunidade à arte-em-comum ${ }^{1}$
}

\author{
Hanka Ottel \\ http://orcid.org/0000-0002-9019-3437 \\ Pascal Gielen' \\ http://orcid.org/0000-0003-2846-4328 \\ I - Univesiteit Antwerpen \\ Antuérpia, Bélgica
}

Resumo: Neste artigo, duas mudanças paralelas são apontadas e sinalizadas. A primeira é a transição da arte-em-comunidade para a assim chamada arte-em-comum; a segunda é a transição da política cultural para a política da cultura. Enquanto a arte-em-comunidade, desde os anos 1990, era regulada, legitimada e, algumas vezes, altamente estimulada pelas políticas culturais oficiais de diversos países europeus, a arte-em-comum - que começou a crescer depois da crise financeira iniciada no final de 2007 - na maioria das vezes não contava com tais intervenções. A primeira é subsidiada pelos governos, pois "compensa" as lacunas estruturais do bem-estar social e, particularmente, se concentra sobre a melhoria social, a coesão e a resiliência. Grandes ativistas e o caráter político radical da última fazem com que a arte-em-comum precise se organizar frequentemente em uma dimensão civil não regulada, que fica entre o mercado e o Estado. Neste artigo, os autores analisam as características da tendência de busca de uma arte-em-comum e articulam a hipótese sobre qual tipo de política serviria de apoio para a ascensão dessa práxis artística.

Palavras-chave: arte-em-comunidade; arte-em-comum; política cultural; política da cultura.

Abstract: When politics becomes unavoidable: from community art to communing art. In this article two parallel shifts are signalized and analysed. One is called the transition from community art to so-called commoning art, the other the transition from cultural policy to a politics

1 Este artigo é uma reprodução da publicação Commonism: A New Aesthetics of the Real, editada por Nico Dockx e Pascal Gielen, páginas 269-280, para a série Antennae - Arts in Society (Amsterdam: Valiz, setembro de 2018). Texto licenciado sob Creative Commons, atribuição de trabalho não comercial e não derivado. Licença 3.0. Traduzido sob a permissão dos autores Hanka Otte e Pascal Gielen e da Editora Valiz (www.valiz.nl). 
of culture. While community art, since the 1990's, was regulated, legitimized and sometimes highly stimulated by the official cultural policies of several European countries, commoning art - which started to boom after the financial crises which started at the end of 2007 is mostly not. The former is supported by governments because it 'compensates' structural gaps in the welfare state and particularly concentrates on social improvement, cohesion and resilience. The highly activist and sometimes radical political character of the latter, makes that commoning artists need to organize themselves in an often not regulated, civil zone between the market and the state. In this article the authors analyse the characteristics of this tendency towards commoning art and they articulate a hypothesis about what kind of politics could be supportive for this rising art praxis.

Keywords: community art; commoning art; cultural policy; politics of culture.

\section{Arte do governo}

Nos tempos atuais, os subsídios públicos voltados às artes diminuíram muito. Sem necessidade alguma de disfarce, os governos anunciam que é complicado buscar formas de legitimar as ações artísticas e de fomentá-las, já que essa é uma área que certamente nem todos consideram importante para os assuntos públicos. Um exemplo disso é que, nos Estados Unidos, o apoio às artes está restrito ao domínio privado e, desde a eleição do presidente Donald Trump, o já modesto subsídio federal para o National Endowment of Arts (NEA) está sob ameaça. Por um curto período de tempo, nos anos 1930, as artes eram consideradas tão importantes para o desenvolvimento dos americanos que programas especiais para a cultura foram lançados. O motivo principal era o de combater o gigantesco desemprego generalizado e que, logo, atingiria também os artistas. A partir do modelo do movimento dos muralistas mexicanos, inúmeros artistas foram convocados para pintar construções públicas, como prédios do governo, escolas, museus, bibliotecas, orfanatos etc. A ideia era a de que a cultura não pertencia exclusivamente ao sublime mundo da arte, mas que todos podiam dela se beneficiar e que todos teriam direito ao desenvolvimento cultural. Na segunda fase do Novo Acordo, após 1965, o Projeto Único Nacional abordava questões que visavam um sistema cultural para todo o país, abarcando nele cinco setores: artes visuais, música, teatro, produção literária e pesquisa histórica e arquivística. Os quatro primeiros empregaram artistas, músicos, profissionais do teatro e escritores, respectivamente, que produziam e mostravam seus trabalhos, gratuitamente ou a preços muito baixos, em todo o país. Essa é a razão pela qual os Programas do Novo Acordo Cultural, de Franklin Roosevelt, são, frequentemente, considerados como o primeiro momento em que a arte se destinava às comunidades. No entanto, alguns críticos começaram a afirmar que, mais tarde, esses programas de Roosevelt serviram como neutralizadores dos trabalhos que continham alguma potência de radicalidade. Eles despotencializavam os movimentos artísticos no momento em que os convertiam em formatos de serviço do governo (ADAMS \& GOLDBARD, 1986: p. 7). 
Era o próprio governo norte-americano que estava desconsiderando a função do público naquele caso, algo que o governo britânico também faria muitos anos depois, na década de 1990, de acordo com Paolo Merli (2002), pois cooptaria os movimentos das comunidades artísticas dos anos 1960 e 1970 e os transformaria em instrumentos políticos². Fortemente influenciado pelo "Uso ou Ornamento?", de François Matarasso (1997) - famoso e também notório relatório daquele período -, o governo britânico argumentava que a arte contribuía para a formação de uma sociedade estável, segura e criativa. No entanto, de acordo com Merli, isso é diametralmente oposto aos objetivos das comunidades artísticas dos anos 1960 e 1970, comunidades estas que ficaram conhecidas por desenvolverem uma "arte de contracultura" por uma razão.

Enquanto [a contracultura] se voltava para as expressões de conflito, a visão de Matarasso se direciona para uma estabilidade social conseguida através de um consenso popular 'pacífico', o que no fundo quer dizer que, à medida que os ricos faziam as coisas 'certas', os pobres deveriam ser acalmados com atividades artísticas 'terapêuticas'. Enquanto que nos anos 1970 o objetivo era a emancipação e a libertação de qualquer forma de controle social, também (e acima de tudo) por meio da criatividade artística; o restabelecimento dos interesses nas artes participativas, defendidas por Matarasso, objetivava restaurar um controle social, que se utilizava das mesmas ferramentas, mas com propósitos bastante distintos (MERLI, 2002, p. 114)

Em países como o Canadá, Austrália, Holanda e Bélgica, a retomada dessas práticas artísticas nos anos 1990 foi bastante relacionada a uma política cultural oficial - tais como o Arts Impact Fund (Reino Unido) e recentemente o Kunst van Impact (Holanda) - que disponibilizaram subsídios para projetos artístico-sociais, ou estimularam o setor privado a fomentá-los, em conjunto com a sociedade, através de todos os tipos de provisões. A maior parte da arte-em-comunidade foi colocada em um domínio regulado tanto civil quanto legalmente (GIELEN \& DIETACHMAIR, 2017).

A política de uma arte-em-comunidade é a legitimação perfeita do aporte público para as artes, especialmente em tempos de austeridade. Afinal de contas, os trabalhos artísticos beneficiam direta e visivelmente a população (a grande pagadora de impostos), especialmente àqueles membros que normalmente não se defrontariam com esse tipo de trabalho. A grande diferença entre a primeira e a terceira onda da arte-em-comunidade diz respeito ao que Roosevelt percebera sobre a importância da relação entre arte e desenvolvimento dos americanos. Os governantes que subsidiam comunidades artísticas desde os anos 1990 têm altas expectativas sobre os efeitos sociais que recaem sobre os indivíduos e diferentes comunidades. Conforme já sugerido por Merli, tais efeitos aparentam se movimentar somente em uma direção de pensamento. Aqueles que valorizam

2 Há aqueles que veem o movimento da comunidade artística que emergiu nos anos 1960 como a origem de um fenômeno (e.g. ADAMS \& GOLDBARD, 1986; GOLDBARD, 2006; MERLI, 2002). 
a arte-em-comunidade podem estar realmente preocupados com a desigualdade e a destruição social, ou com qualquer outra injustiça que afeta a sociedade. E é justamente por essa razão que essas pessoas, através de seus trabalhos, tentam contribuir com o aprimoramento do tecido social. No entanto, há críticas já bastante difundidas a respeito desse assunto e que se perguntam se, de fato, esses movimentos são ou não trabalhos sociais. Reflexões mais antigas sobre o fenômeno da arte-em-comunidade afirmam que, na pior das hipóteses, essa é uma ideia proveniente do conceito de "poder pastoral", desenvolvido por Michel Foucault (FOUCAULT, 1977-1978). Os trabalhadores sociais podem ser considerados como aqueles que ajudam o estado, e mesmo a política, na medida em que detectam, documentam e tentam corrigir comportamentos que não estão de acordo com valores e normas pré-estabelecidos em uma sociedade. Eles não apenas ajudam os desempregados, drogados, viciados e adolescentes rebeldes, como também tentam colocá-los na linha quando monitoram, por exemplo, a quantidade de escovas de dentes e camas presentes nas casas daqueles que recebem algum tipo de benefício público. A partir de um entendimento específico sobre trabalho social, esses agentes são responsáveis por manter, através de princípios disciplinarizadores, uma certa normalidade na sociedade. Isso não pode ser tratado como um aspecto sem importância, uma vez que tal entendimento de trabalho social considera a existência de uma ordem que não precisa ser questionada. Desta forma, o trabalho social contribui, principalmente, com a socialização e a integração dentro de uma hierarquia de valores culturais já dada, sem que seja necessário mexer em nada. Algo muito semelhante ocorre nos processos de trabalhos de arte-em-comunidade. Por exemplo, quando são distribuídas câmeras de vídeos em um bairro carente para que as pessoas filmem e entrevistem uns aos outros, como forma de construir uma imagem coesa a partir de indivíduos e famílias que supostamente não convivem socialmente entre si; ou também quando dirigem uma cena para que todos atuem em conjunto. O resultado dessa "abordagem processual" normalmente é apresentado, ou em uma exibição pública festiva, ou em uma em que políticos, funcionários públicos e imprensa estejam na plateia. Esse tipo de gesto expõe detalhes às vezes muito íntimos como, por exemplo, uma profunda miséria, repleta de condições de vida muito empobrecidas. Enquanto os trabalhadores do setor social lidam profissionalmente de modo confidencial com as informações de cada pessoa, a arte-emcomunidade as expõem como se fossem confissões públicas.

Obviamente, nem todas as práticas de arte-em-comunidade participam dessa maquinaria de controle social. Não se pode deixar de notar, contudo, que em um passado não tão distante, as ações artísticas em comunidades - orquestradas ou não por aportes governamentais - eram desenvolvidas em bairros e regiões que tinham os centros médicos locais e as escolas como os grandes responsáveis pela coesão social. Sob a ação de administrações públicas que buscavam enxugar orçamentos, esses locais foram fechados, fundidos ou centralizados. Coincidentemente ou não, alguns anos depois dessas operações 
de austeridade, práticas de arte-em-comunidade começaram a acontecer nas mesmas localidades, sendo pagas por algum fundo financeiro da política local. Os artistas dessas práticas tentavam resgatar uma forma de sociabilidade desenvolvida anteriormente e que havia sido apagada pelas novas políticas. O formato de intervenção governamental feito através de projetos artísticos tem, de algum modo, um baixo custo-benefício, pois se trata de um investimento temporário e mais barato do que manter a estrutura de uma escola ou de um centro médico, espaços que demandam funcionários permanentes. E para além de tudo isso, no período de encerramento desses projetos temporários, os artistas frequentemente produzem algo que é apresentado publicamente, trabalhos que, na maioria das vezes, mostram a resiliência do bairro, com pessoas criativas e repletas de alegria. Imagens positivas como essa são sempre muito bem-vindas em épocas de eleições; no entanto, sabe-se que a arte-em-comunidade somente maquia os buracos deixados pelos políticos em todo o cerne social.

É importante frisar que cada vez mais os praticantes de arte-em-comunidade estão conscientes das armadilhas que acompanham os comícios governamentais. Todavia, sentem dificuldade de se posicionarem criticamente perante àqueles que os chamam para trabalhar e que pagam os seus salários. Seja em uma comunidade que é mantida através de recursos públicos, seja em uma mantida por recursos privados, em nenhum dos casos as instituições se mostram abertas aos questionamentos políticos feitos por artistas. Da mesma forma que Ai Weiwei não foi patrocinado pela LEGO $^{\circledR}$ por ser um "artista politizado", os subsídios são prontamente cortados tão logo os artistas comecem a mostrar indícios de engajamento político.

\section{Imaginação monocultural}

A implementação da arte-em-comunidade tem contribuído com a integração e a socialização a partir de uma ordem cultural dominante. Atualmente, cada vez mais os governos se utilizam de recursos nostálgicos para criar um sentimento de coesão social a partir de uma ideia de um "nós" supostamente integrado. Essa é uma forma de coesão que se baseia no reconhecimento e nas similaridades entre os indivíduos que formam um grupo e nas características que marcam a prosperidade de algumas comunidades. No entanto, devido à globalização, à digitalização e à migração, comunidades homogêneas têm se tornado altamente escassas. Especialmente nos grandes centros urbanos, pode-se notar a presença de maiorias e de minorias que formam o tecido populacional, embora a maior parte das pessoas ainda pertença às minorias sociais. Ao mesmo tempo, cidades pequenas e zonas rurais vêm se tornando mais diversas, fator este que não se deve somente aos diferentes repertórios culturais, mas também às questões de status, classe social, idade, gênero, LGBT e renda. Com muita frequência, a hiperdiversidade tem sido vista como a causa de ataques violentos e de muitas manifestações, tais como nos banlieues de Paris, 
nos subúrbios de Londres, em Haia ou nas vizinhanças de Molenbeek, em Bruxelas. Não há perspectivas para que haja aproximações entre as diferentes crenças e culturas. Pelo contrário, cada vez mais indivíduos e grupos vêm se direcionando para um beco sem saída, onde a violência parece ser o único recurso possível para lidar com as diferenças.

De acordo com o estudioso da cultura Christiaan De Beukelaer (2017), os impasses têm como causa mais as relações de poder desbalanceadas do que as diferenças de opinião. Em uma sociedade que é hiperdiversa, a maioria deixa de ser homogênea e se torna um composto de inúmeras formas de minorias (ROSANVALLON, 2012). Mesmo assim, é uma certa minoria (geralmente branca e de classe média) que continua a exercer o poder, como se fosse a grande maioria. Esse gesto faz com que se mantenha um imaginário de uma nação monocultural que, de acordo com De Beukelaer, é construída a partir de uma política cultural com base metodológica nacionalista. Os discursos nacionalistas nem sempre são explícitos, mas certamente são nutridos tanto no núcleo como em todas as ramificações da organização administrativa. Em um país como a Holanda, por exemplo, isso fica bastante evidente quando se diz que o cânone das artes foi, nos últimos anos, repentinamente atacado pela cultura popular ou quando, mais recentemente, há uma exaltação do hino nacional. A ideia de um suposto consenso cultural construído na população através de métodos nacionalistas, faz com que sejam aumentados os riscos de conflitos. Não apenas porque essa aparente imagem de uma comunidade harmoniosa pertence a um certo passado que não existe mais, mas especialmente porque aqueles que formulam a política fazem desse imaginário um instrumento de poder. Apegar-se a uma ideia de consenso permite que o dissenso e as diversidades sejam constantemente apagados e as tensões sejam varridas para debaixo do tapete, ações que fortalecem uma valoração artificializada de um "nós" e que criam uma coesão social vinculativa. Conforme mencionado anteriormente, a arte-em-comunidade tem um papel significativo para contribuir com esse cenário e é por isso que inúmeros políticos têm apoiado ações artísticas que direcionam seus trabalhos à comunidade.

A realidade social das minorias requer políticas radicalmente diferentes. Ainda que essas políticas desejem a coesão social, elas têm que aprender a lidar com as diferenças. Trata-se de uma coesão social que não se baseia em um consenso, mas que, paradoxalmente, opera através de um dissenso compartilhado. O foco não está em ligar as pessoas, mas em construir caminhos entre elas; não em encobrir as contradições e as tensões, mas aprender a reconhecer o Outro, assim como a conviver com ele enquanto ser que é radicalmente diferente. Os métodos nacionalistas utilizados pelas políticas culturais não contribuem, atualmente, para que sejam superados os imensos contrastes entre o "nós" e o "eles". Por esse motivo, De Beukelaer defende que reavaliemos o debate sobre identidade e o significado do espaço público. Não devemos mais considerar a identidade como algo único, mas algo que deve ser sempre negociável, tal como uma política "metodológica cosmopolita" - que, para simplificar, passaremos a chamar 
de "cosmopolítica". Ela se inicia no respeito aos semelhantes, independentemente da identidade nacional (DE BEUKELAER, 2017). As políticas culturais e os trabalhos artísticos que convergem com essa ideia não têm mais a intenção de construir socializações ou um comportamento que seja coeso. Pelo contrário, devem encontrar um caminho que lide com as diferenças de fundamentos. A coesão social e a homogeneização não são mais as grandes questões que se passam no interior de uma comunidade, apesar de serem pontos centrais em todo o mundo externo a ela. Paradoxalmente, esse mundo externo tem se internalizado em diversas comunidades, igualizando, com isso, as diferenças que as constituem.

\section{Arte como um assunto público}

Alguns estudos têm mostrado uma relação entre uma arte cujos propósitos são questionadores e uma coesão social externa que é feita através de pontes (OTTE, 2015). A arte como um dispositivo que lida com a imaginação remete sempre a alguma realidade. Esta é interpretada de modo idiossincrático através de nossa imaginação, que pode simplesmente refleti-la e confirmá-la, ou pode desestabilizar nossas experiências já constituídas sobre aquilo que convencionamos como real. No primeiro caso, a arte confirma a medida de uma cultura (os valores existentes, as normas, ou a ordem social dominante). No segundo caso, ela desestabiliza esses fatores e às vezes ainda pode proporcionar a criação de novos (GIELEN \& LIJSTER, 2015). Muitas das políticas culturais participativas de hoje são geridas a partir da primeira forma, criando, assim, o que podemos chamar de "arte confirmativa". A arte-em-comunidade e os projetos participativos recorrem a essa natureza de arte, não somente pelo fato de o financiamento para esse tipo de projeto ser mais fácil; mas também por razões de ordem pragmática. Quando esses artistas desejam alcançar novos públicos, eles se apoiam em valores culturais e normas com os quais esses outros públicos têm familiaridade. Circunscrever um domínio que faça com que as pessoas se reconheçam é também aumentar as possibilidades de participação delas. O resultado, entretanto, é o mesmo: quando a coesão social é absolutamente alcançada, o que está em jogo é a homogeneização interna e o crescimento de um sentimento coletivo de um "nós".

Grande parte das políticas culturais que fomentam as artes mais subversivas ainda o fazem em espaços seguros, como dentro de museus ou de teatros. Neles, há salas específicas para as experimentações, sendo a transgressão, o dissenso e a controvérsia conceitos bem-vindos a esses espaços. No entanto, dentro dos habituais espaços das artes, as provocações das convenções culturais se destinam principalmente às pessoas da classe média (brancas em sua maioria), que encaram a visita desses espaços como se fosse algum tipo de aventura. Em resumo, essa é uma classe que confirma seus próprios valores e normas com pequenas doses semanais ou mensais de imaginação. Os desafios são bons, até mesmo necessários, mas preferencialmente dentro das paredes seguras da ficção, porque tão logo esses amantes da arte saem do teatro ou do museu, a ordem diária 
das coisas volta a se impor. Os artistas que ousam se aventurar fora dessas paredes, utilizando códigos desobedientes e questionadores da arte contemporânea, frequentemente correm o risco de não serem ouvidos. A jogada "artística" não encontra conexão com qualquer contingente de público, já que ele carece do repertório dos códigos e convenções da arte contemporânea. Existe um dilema tanto em artistas que desenvolvem uma arteem-comunidade, quanto naqueles que elaboram as políticas públicas, que pensam que a legitimação dos fundos públicos destinados às artes só são justificáveis quando ela é oferecida de modo direto à comunidade. A partir do momento em que um potencial público não é vislumbrado e certos trabalhos sinalizam traços políticos, é preferível manter os artistas dentro dos moldes do mundo oficial. O historiador da arte e filósofo Steven ten Thije (2017) aponta que isso decorre de um individualismo que tem se tornado a norma da política cultural. Conclui que, na Holanda, as discussões em torno da política cultural são normalmente sobre a tensão entre o grau de interferência governamental na arte e a asseguração de sua autonomia, mas nunca sobre o valor público da arte. De um lado desse debate, vemos os liberais que acham que as artes (bem como qualquer outra coisa) serão mais desenvolvidas se estiverem sob os princípios do mercado. Isso não significa que não haja valor na arte, mas que tal valor é limitado à esfera privada e pessoal. Do outro lado do debate, há uma perspectiva socialdemocrata, para a qual é evidente que a arte tem uma relação com a sociedade, mas que se dá somente através do indivíduo que a produz ou que a contempla. O valor da arte, neste caso, reside na emancipação individual. Em nenhuma das visões é possível encontrar um valor público da arte, ou seja, uma arte que contribui diretamente com processos civis, sendo com isso, também, política. Ideologicamente, nas duas visões, aqueles que formulam as políticas têm tentado legitimar os fundos públicos das artes, mas têm o feito em solos arenosos, conclui Thije. As instituições culturais têm cada vez mais justificado suas existências com base nos números de seus visitantes. No entanto, valorizar a arte a partir de critérios que consideram uma grande soma de indivíduos não é uma questão pública.

\footnotetext{
De acordo com Rancière, a arte contribui com a vida pública, não por ser apreciada por muitos, e sim pelo fato de que contribui para que a comunidade lide com conflitos e diferenças que existem dentro dela. Se a questão do fomento às criações artísticas continuar travada no domínio de suas popularidades, as artes permanecerão ainda presas nas diferentes formas de exclusividade (THIJE, 2017: p. 84).
}

Se o gosto pela arte é visto como algo que concerne ao indivíduo ou a um grupo específico, a lógica que segue esse raciocínio é de que a responsabilidade pela produção artística é dessas pessoas. A questão é que, hoje, tanto os liberais quanto os socialdemocratas, que se baseiam nos valores nacionalistas descritos anteriormente, enxergam a arte como uma dimensão privada voltada à classe média - uma minoria que ainda acredita ser a maioria. As duas correntes defendem, na verdade, um ponto de 
vista liberal - ou melhor, neoliberal - com um posicionamento eurocêntrico, para quem a cultura (ocidental) é uma questão de gosto individual e de liberdade de escolha. A partir da análise do desenvolvimento da política cultural e de seus recursos na Holanda ou em qualquer outro lugar da Europa - desde os subsídios e das chamadas "ajudas" dos programas culturais, até as políticas que se baseiam em auditorias -, é possível concluir que os paradigmas mencionados acima não somente se mantêm, como também são cultivados através de um modo que se dá unilateralmente. Se temas como o da indústria cultural e a liderança de empreendedores, ou sobre a arte participativa e cidadania ativa são pautados, eles o são por uma minoria que ainda pensa ser a maioria; uma minoria que crê que a sua cultura não é somente homogênea, mas acredita também que desenvolve a cultura "correta". Não é de se admirar, com isso, que a política cultural seja muitas vezes tratada de uma forma ainda muito paternalista.

\section{O que está por vir: a arte-em-comum}

Os valores predominantes da atual política cultural têm aumentado o número de artistas e de outros profissionais da cultura que se sentem prejudicados. Incluem-se aqui os artistas que desenvolvem arte-em-comunidade. Por toda parte do mundo, diversas iniciativas artísticas têm emergido, investigando novas metodologias de existência. Isso porque, ou não mais se encaixam nos modelos atuais das políticas culturais, ou porque simplesmente precisam criar alternativas às medidas de austeridade e à falta de interesse privado. Os artistas que ignoram a estrutura regulada, ou seja, a estrutura civil, e que se empenham na esfera política, frequentemente se encontram em uma zona limiar, uma zona cinzenta entre o mercado e o governo, e algumas vezes também entre a criatividade e a ilegalidade (GIELEN \& DIETACHMAIR, 2017). Artistas que expressam seus engajamentos políticos fora dos museus ou de outros redutos artísticos, que não se preocupam somente com a esfera social, mas também com a esfera política, são rapidamente desprovidos de patrocinadores, subsídios ou de apoio institucional. O duplo percurso no nível social e político mostra-se como uma possibilidade de criação de métodos alternativos de trabalho e de financiamento. Essa é uma indagação que orienta algumas iniciativas culturais, tais como Culture to Commons (Zagreb), Recetas Urbanas (Sevilla) e I'Asilo (Naples), para nomear somente algumas de muitas outras que estão em busca do domínio dos Commons ${ }^{3}$, um espaço social onde essas iniciativas podem encontrar uma certa liberdade e suporte para seus trabalhos.

Uma das portas de entrada para os commons é, talvez, a reciprocidade. Aqueles que se beneficiam dos bens que são partilhados só o podem fazer (e continuar a fazê-lo) se também contribuírem com os commons. Em outras palavras, as pessoas são colocadas

3 Uma tradução possível para Commons seria a de "bem comum". No entanto, a lógica desenvolvida pelos autores sobrevoa campos que vão para além da partilha de objetos e produtos, atravessando um entendimento que coloca a ideia de comum também enquanto um princípio metodológico (N.T.). 
em uma posição de contínua colaboração: geram, de um modo independente, novos produtos e serviços, materiais ou imateriais, que ficam disponíveis para todos. Por essa razão, preferimos chamar a arte-em-comunidade de arte-em-comum, pelo fato de não haver aderência às necessidades civis, e por não atuarem nem no mercado, nem no domínio público dos governos. Afinal, aqueles que lidam com a arte-em-comum não se beneficiam somente dos bens que sempre produzem com suas práticas como também, a partir delas, criam novas possibilidades de ação. Os artistas que operam sob a lógica da arte-em-comum conseguem, desta forma, ser mais autônomos do que seus colegas que atuam sob a lógica da arte-em-comunidade, sendo também mais autônomos do que os "tradicionais" artistas modernos e contemporâneos que vivem em função do mercado e do governo. Esses últimos podem defender sua autonomia e idiossincrasia somente discursiva e artisticamente, uma vez que têm seus trabalhos financiados, ou pelo mercado, ou pelo governo. Os artistas do comum, de modo contrário, podem se posicionar tanto política, quanto economicamente, de um modo autônomo, devido à auto-organização. Isso só é possível por conta do sistema social de reciprocidade, conforme já mencionado. A arte que é desenvolvida pelos artistas do comum é, portanto, radicalmente diferente daquela que é desenvolvida por seus colegas. O trabalho certamente é singular e autônomo e isso não faz com que ele seja individual nem que uma suposta particularidade interna seja o ponto de partida. Também não se trata de uma estratégia ou movimento conceitual que deseja enquadrá-lo na competição corrente do mundo da arte. Ainda que os artistas do comum se relacionem fortemente com o contexto, este não é o do mundo profissional da arte. Em primeiro lugar, é a própria realidade social desses artistas que está em jogo. Dentre outras coisas, os seus trabalhos autônomos ou suas contribuições singulares consistem, primeiramente, em capturar, e só então canalizar uma criatividade compartilhada. Este é o modo como os artistas do comum produzem e operam a partir dos commons. Eles vivem, por assim dizer, de ideias criativas, mas também das questões e necessidades de uma comunidade específica. A singularidade da contribuição se dá através da materialização dessas ideias, ofertando respostas que podem ser subversivas e até mesmo inesperadas pelo coletivo. Tal estratégia é a única maneira de manter os commons abertos, permitindo também que o ambiente cultural se mantenha vivo. Os artistas do comum também consideram mais fácil de se relacionar com a já mencionada cosmopolítica, justamente porque sua criatividade e chance de sobrevivência, assim como para todos os outros que participam de um ambiente comum, existem somente graças à diversidade e, portanto, à permanente abertura e conexão com o Outro.

As possibilidades de configuração de uma política cultural cosmopolítica não se resumem aos exemplos dados neste ensaio. Sabemos, no entanto, que uma política do comum será uma política que se desenvolverá primeiramente nas bases da sociedade. As coisas não serão mais feitas hierarquicamente, através dos princípios da social democracia e do neoliberalismo, nem muito menos do ultrapassado comunismo. 
Em sua própria natureza, a cosmopolítica é, ao invés de comunista, comum-ista, isso porque aqueles que fazem parte do comum, incluindo aqui os artistas do comum, são os que fazem suas próprias leis e que produzem suas próprias estruturas logísticas e financeiras. O trabalho e a vida diária das pessoas que partilham do comum são sempre políticos por natureza: essas pessoas estão constantemente pensando sobre e modulando as maneiras de se viver em conjunto. Um governo cosmopolítico não seria nada mais do que um órgão regulador, responsável por conferir se as autolegislações e autorregulações dos corpos seguem os princípios constitucionais - por exemplo, se são democráticas, indiscriminatórias e se protegem a liberdade e a privacidade - confirmando, desta forma, a legalidade de suas práticas. Todas as decisões restantes ficam a cargo dos que vivem no ambiente comum, que constituem a democracia básica através das assembleias. Esse tipo de política aparenta ser bastante difícil de ser realizada, mas talvez seja essa a única saída para abordar a complexidade emergente do aumento das minorias sociais.

Hanka Otte é pesquisadora de pós-doutorado no Culture Commons Quest Office (Antwerp Research Institute for the Arts - ARIA). Tal grupo de pesquisa tem pensado como os trabalhos criativos podem contribuir com o ambiente urbano e o que tem sido chamado de "commons", bem como a emergência de biótopos criativos. A autora tem como foco a análise desses biótopos, pensando no modo como eles têm se mantido de forma sustentável através das políticas das cidades. Sua pesquisa de doutorado foi acerca da relação entre a participação artística e a coesão social. Defendeu sua tese sob o título de "Binding or Bridging, on the relation between arts, cultural policy and social cohesion" [Ligar ou abrir caminhos, sobre a relação entre artes, política cultural e coesão social], em outubro de 2015, na Groningen University.

hanka.otte@uantwerpen.be

Pascal Gielen é professor de sociologia cultural no Antwerp Research Institute for the Arts (ARIA). Em 2016, recebeu o Odysseus Grant of the Flemish Scientific Fund por sua excelente pesquisa internacional. Com essa subvenção, criou o grupo interdisciplinar Culture Commons Quest Office, cuja pesquisa é voltada às condições de sustentabilidade de trabalhos criativos em diferentes contextos urbanos. Gielen também é editor chefe da série internacional de livros Arts in Society.

pascal.gielen@uantwerpen.be

Tradução de Rodrigo Monteiro 


\section{Referências}

ADAMS, D.; GOLDBARD, A. New Deal Cultural Problems: Experiments in Cultural Democracy. Webster's World of Cultural Democracy (wwcd.org), 1995.

DE BEUKELAER, C. Ordinary Culture in a World of Strangers: Toward Cosmopolitan Cultural Policy. In: Internacional Journal of Cultural Policy. Londres: Routledge, 2017. (DOI:10.1080/10286632.2 017.1389913)

FOUCAULT, M. Security; Territory; Population: Lectures at the Collège de France, 1977-1978. Trad. Graham Burchell. New York e Basingstoke: Palgrave Macmillan, 2007.

GIELEN, P.; DIETACHMAIR, P. Public, Civil and Civic Spaces. In: GIELEN, P.; DIETACHMAIR, P. (orgs). The Art of Civil Action: Political Space and Political Dissent, pp. 11-33. Amsterdam: Valiz, 2017.

GIELEN, P.; LIJSTER, T. Culture: The Substructure for a European Common. In: GIELEN, P. (org). No Culture No Europe: On The Foundation of Politics, pp. 19-66. Amsterdam: Valiz, 2015.

GIELEN, P. Mapping Community Art. In: DE BRUYNE, P.; GIELEN, P. (orgs). Community Art: The Politics of Trespassing. Amsterdam: Valiz, 2011.

GOLDBARD, A. New Creativity Community: The Art of Cultural Development. Oakland, CA: New Village Press, 2006.

MATARASSO, F. Use or Ornament? The Social Impact of Participation in the Arts. London: Commedia, 1997.

MERLI, P. Evaluating the Social Impact of Participation in Arts Activities. In: International Journal of Cultural Policy. 8, $\mathrm{n}^{\circ} 1$ pp 107-118. Londres: Routledge, 2002.

OTTE, H. Binden of Overbruggen? Over de relatie tussen kunst, cultuurbeleid en sociale cohesie. Tese de Doutorado. Groningen: Rijksuniversiteit Groningen, 2015.

ROSANVALLON, P. Democratie en tegendemocratie. Amsterdam: Boom, 2012.

THIJE, S. T. The Blind Spot: Arts and Politics in the Netherlands. In: BOOMGAARD, J; BROM, R. (orgs). Being Public: How Art Creates the Public. Amsterdam: Valiz, 2017. 